\title{
REPORT FROM AUSTRALIA
}

I

In many ways it is attractive and fruitful to view the total history of Australia itself within the expansive conceptual framework of "European Expansion and the Reactions to $I t^{\prime \prime}$, but this applies in particular to the establishment of the white Christian societies of the British colonies, and to their relationship with the aboriginal inhabitants of the country. It may therefore be appropriate to start this 'Report from Australia' with a reference to the project "AUSTRALIA 1788-1988: A BICENTENNIAL HISTORY". Intended as the contribution from the historical profession to the celebration of the 200th anniversary of the foundation of the colony of New South Wales, and with that the white invasion of Australia, it follows in the footsteps of similar outbreaks of commemorative madness, such as Vancouver, 1978, bicentenary of Cook's landing at Nootka Sound; Perth, 1979, sesquicentenary of the foundation of Western Australia. The project will consist of two series of volumes, one of reference works (historical atlas, historical statistics, dictionary), the other of historical works. The main objective of the series is to offer an analytical and interpretative picture of Australia in so-called "slice-years" each taken with fifty years intervals. Thus, the middle three volumes will be devoted to 1838,1888 and 1938 respectively, while the first will deal with aboriginal history until 1788 and in a minor section - the coming of the Europeans, while the fifth and last volume will be a more conventional survey of the period 1938 - 1988 .

Reflecting, and probably reinforcing, recent trends in Australian historiography, much space will be given to a comprehensive investigation of the contacts between the European and the aborigines in which factors of geography,. topography and land use are expected to be emphasized. This applies in particular to the volume for 1838 , in which year the white settlements - as yet not more than a collection of islands separated by vast distances of sea or bush - counted a population still smaller in numbers than that of all indigenous tribes.

In the $1830 \mathrm{~s}$ a series of massacres took place on the rapidly moving frontiers that indicated the flood line of the waves of white settlements on the black continent, but whereas a 'modern' discussion of these has already come underway, the whole range of white-black relationships on the farms and stations, in the country towns and cities still has to begin. General Editor of the historical volumes, is Professor Ken Ingliss, Department of History, RSSS, ANU. 
While the 'Bicentennial Project' will foremost be a collective undertaking, at the same time Oxford University Press has commissioned a 4 volume OXFORD HISTORY OF AUSTRALIA, to be completed in 1984. Organized in the more conventional, chronologically sequential order, the volumes will mirror in a similar fashion recent trends toward a greater interest in race and ethnic relations in Australia. General editor of the series is Professor G.C. Bolton of Murdoch University (Murdoch, W.A.). A potential third prong to this upsurge in 'contact history' proved so short-lived that one can hardly speak of it having been aborted. A NATIONAL MUSEUM OF AUSTRALIA HISTORY, of which the foundation was recently foreshadowed, had also to devote special attention to this subject. Yesterday, however, when the recommendations of the Federal Government's "razor gang" for cutbacks in the public sector were divulged, the National Museum was amongst its victims .

III

In Itinerario $1979 / 2$ (pp. 34 - 36) a brief account was given of the proceedings of the International Conference of Indian Ocean Studies (ICIOS), held in August 1979 at the University of Western Australia. Several developments have resulted from this, two of which are of interest here. Firstly, the production and circulation has started of an INDIAN OCEAN NEWSLETTER; (vol. 1 appeared in April 1980, vol. 2 in December 1980). It contains information about all kinds of activities (publications, conferences, organisations and journals, museums and maritime archaeology, etc.) relating to the history of the region - in its diversity a grandiose setting for the study of European expansion and the reactions to it. The editor of the newsletter is Dr. Kenneth McPherson, Centre for South and Southeast Asian Studies, University of Western Australia, Nedlands, W.A. 6009. Secondly, the recommendations of the UNESCO working party on the future of Indian Ocean Studies based on the conviction that "port cities" constituted an area of study that required the urgent attention of scholars, were accepted by UNESCO and are now in the first phase of being implemented.

IV

Peter Reeves, of the University of W.A., with Kenneth McPherson and Frank Broeze are preparing an analytical BIBLIOGRAPHY OF PORT CITIES IN THE INDIAN OCEAN REGION, with attached a directory of institutions and scholars working in the field. Although this survey will not be limited to the period of European 
intrusion and within that period will also cover subjects not immediately related to European expansion, aspects of this expansion and its reverberations will obviously constitute a prominent part. The General Assembly of Unesco has in the meantime accepted that

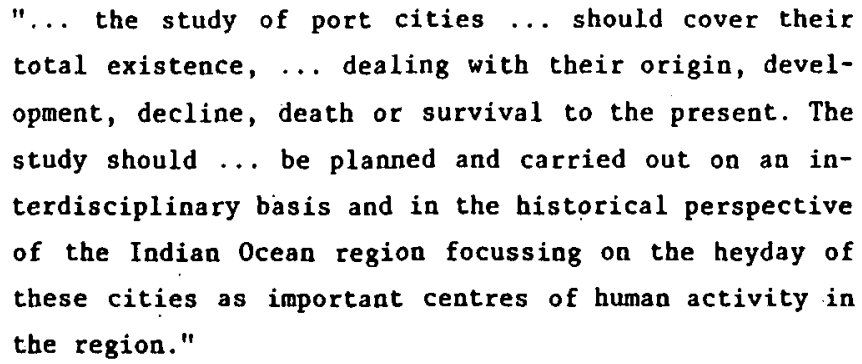

In order to implement this programme, Unesco National Comrissions has been asked:

"... to communicate to Unesco, by 15 May 1981, names of port cities together with their characteristics, their historical background and present state. ... On the basis of the information received Unesco will prepare a provisional annotated list of port cities. ... A regional meeting of a small number of experts will then be convened in order to examine the list, to select the cities, and to prepare a programme of study of the cities thus selected. The programme will be communicated to the National Commissions and research institutions in the region."

In view of recent conferences on colonial port cities (University of California) and colonial cities (at the Leyden Centre) the Unesco project seems to be welltimed and may stimulate research within and, it is hoped, also outside the region.

V

Related to the Unesco programe on port cities is a project of Professor Ashin Das Gupta, of Visva Bharati, Santiniketan, and Dr. M.N. Pearson, of the 
University of New South Wales, who are coediting a book to be called INDIA AND THE INDIAN OCEAN, 1500-1800. Some 18 potential contributors have been approached, and the response has been extremely positive and encouraging.

The book willinclude two sorts of essays. Longer ones of up to 12,000 words which will provide general surveys: Denys Lombard, The Indian Ocean in the Fifteenth Century, and C.R. de Silva, Sri Lanka and the Indian Ocean. A second group of up to 8,000 words, will deal with more specific themes: Lotika Varadarajan, Traditional Navigational Techniques, and Peter Marshall, The Private British Merchant and the Indian Ocean. In general these essays will provide benchmarks of our present knowledge, rather than be based on new research. The contributors will reflect on areas of research to which they have already made substantial contributions, tell us what is known at present, and what needs to be done.

The book will also explicitly attempt to look at the Indian Ocean as a unit, and try to avoid overemphasizing European activities. Rather it is hoped to explore and present the world of the Indian Ocean, with European concerns and the European private merchants seen as parts of the Indian Ocean structure. The book will include an introduction and bibliographies, and in sum it is hoped, will introduce the subject, help in its teaching, and suggest areas where future research could profitably be undertaken. It is intended to receive all contributions by mid 1981; publication in India will follow at once. For further information write to:

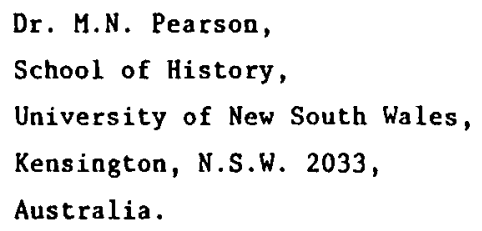

VI

Two conferences are scheduled that may be of interest to readers of Itinerario.

The SOUTH ASIA STUDIES ASSOCIATION OF AUSTRALIA will meet from 24 - 26 August 1981 at the University of New England. Plans are to organise a number of panel sessions around three themes. These are:

1. South Asia in Australian education

2. Orthodoxy in Indian religion

3. Arts in South Asia 
While the last two themes are more specifically regional in character, the first offers a range of aspects that are by no means restricted to South Asia or Australia:

Teaching of Civilization Courses: aims, approaches and problems, Teaching of Religion,

Teaching South Asian politics,

Teaching about South Asian society,

Teaching imperialism, nationalism, modern political history,

Teaching of South Asian languages,

Thematic approaches to teaching South Asia,

South Asia in Secondary Education: History, Social Studies.

Further information on this conference can be had from:

Professor S. Arasaratnam,

Convenor, Organising Committee SASA,

Department of History,

University of New England,

Armidale, N.S.W. 2351,

Australia .

VII

The second conference planned to be held at the Australian National University (Canberra) sometime early in 1982 (perbaps May 1982) will be devoted to the theme "INDONESIAN-MELANESIAN TRADE AND EXCHANGE".

The theme of the conference has been chosen to bring together scholars working in two areas (Indonesia and Melanesia) and in a number of disciplines, to help to unite two areas which have up to now remained separate. An accident of geography and the recent colonial pasts of Indonesia and Melanesia have helped to create a separation of interests and regional specialisations. Irian Jaya is an area neglected by both Indonesian and Melanesian specialists and thus a boundary exists between the two areas of study. Those working in Melanesia tend to concentrate in the east of the region and to look eastwards. towards the outer island world of Melanesia; it is hoped that this Conference will encourage them to look westwards towards Indonesia. In their turn those working in Indonesia tend to look westwards towards the larger islands of the archipelago, the Malay Peninsula and mainland Southeast Asia; it is hoped that these people will look eastwards towards Melanesia. It is obvious that in terms of natural history, prehistory, history and culture the two areas are connected. 
The theme 'trade and exchange' has been chosen to narrow the field of discussion and also because it is an obvious medium in which to examine and to trace the connections between the two areas.

It is suggested that in order to focus discussion that the Conference be divided into two sections which then concentrate on specific themes (but neither the sections nor the themes should be regarded as final, and any other suggestions are welcomed).

1. The recent past, (i.e. post-1500 AD). This section will concentrate on the historical and ethnographic evidence for trade and exchange between the two areas. The emphasis will be on Eastern Indonesia and the links eastwards as these are the easiest to document and so Indonesian experts will predominate in this section. The themes are:

(a) The relationships between supply and demand with emphasis on the collectors and distributors of goods.

(b) The nature and extent of political control in the areas, particularly how control was exercised and enforced in a trading situation.

(c) The flexibiblity of trade and exchange sytems, how, why and when they altered.

2. The long term view. This section will take a longer term view of the problem and will utilise material from the first section but with the addition of new forms of evidence from the following disciplines:

(a) Prehistory - the emphasis here will be Melanesian due mainly to the paucity of evidence from Indonesia.

(b) Linguistics - the linguists have already made contributious to connecting Indonesia and Melanesia.

(c) Natural History - particularly the movement of plants and animals by man in both directions.

For suggestions, requests for further information, etc. write to

Dr. James Urry,

Department of Prehistory and Anthropology,

The Faculty of Arts,

Australian National University,

P.0. Box 4,

Canberra, A.C.T. 2600;

Australia. 
VIII

Finally, mention must be made of the establishment of a new and innovative undergraduate course (at 2nd/3rd year level) at the University of Western Australia. Entitled EUROPE AND AFRICA, 1500-1960, the unit will be controlled by Ms. Penny Hetherington, the author of British Paternalism and Africa, 1920 1940 (London, Frank Cass, 1978).

Europe and Africa is a broad survey course which is intended to introduce students to the study of African history. The greatest body of literature on Africa still concerns some aspect of contact between Africa and the outside world. However there is a large body of material, both pioneering and revisionist, on which to base an Africa-centric history.

The course will begin with an examination of the continent's geographical setting and its pre-history, the extent of contact between Europe and Africa in the Ancient World and the spread of Islam into North Africa. This introduction to the course will also include a consideration of attempts to write the history of Africa for the period before the 15th century. The lecture programme for the rest of the course will be organized chronologically, beginning with the first contact between Portugal and West Africa in the $15 \mathrm{th}$ century and ending with the liquidation of the Colonial Empires in Africa in th 1960 's. There are obvious themes which are central to much of the literature including the slave trade, the conflicts between Boer, Bantu and the British, the partition of Africa by European powers and the spread of colonial administration. While these themes will be present, the emphasis will be on the history of African societies and thier responses to Europe. The emphasis for the 20th century, for example, will be on the African response to colonial rule rather than on the history of European administration in Africa.

The lecture framework will provide the background for more specialist work at tutorial level. Recent monographs, collections of essays around particular themes and a great variety of material in journal articles will form the basis for an examination of many aspects of African society and politics.

\section{Preliminary reading}

- Collins, R.o. (ed.) Problems in African History (Prentice-Hall 1968).

- McEwan, P.J.M. and Sutcliffe, R.B. The study of Africa (University. Paperbacks 1965). 


\title{
Text Books
}

- Boateng, E.A. A Political Geography of Africa (Cambridge University Press 1978).

- Curtin, P., Feuerman, S., Thompson, L., Vansina, J., African History (Little Brown, Boston, 1978).

- McEvedy, C. The Penguin Atlas of African History (1980).

\author{
Frank Broeze \\ Department of History
}

The University of Western Australia

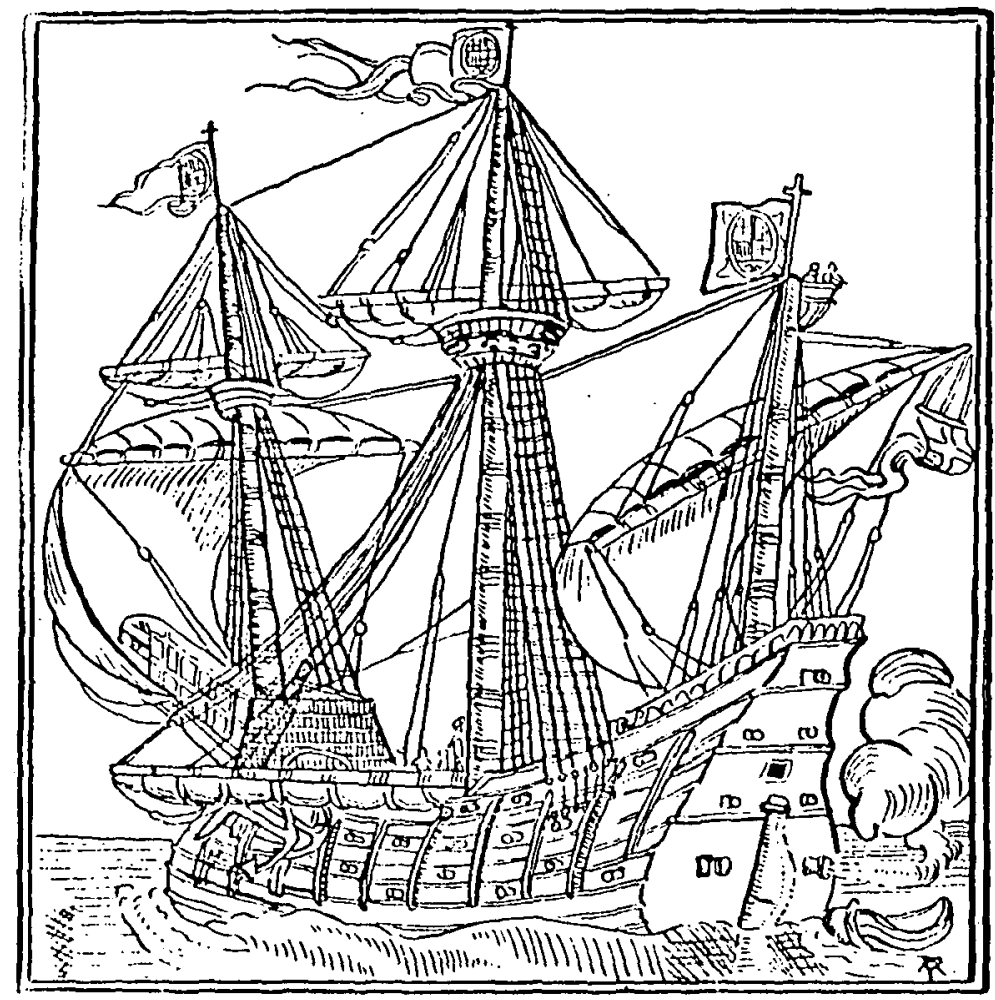

